\title{
UMA ATIVIDADE PARA OS ANOS INICIAIS ENVOLVENDO PROPRIEDADES DO SISTEMA DE NUMERAÇÃO MAIA
}

\section{AN ACTIVITY FOR THE ELEMENTARY SCHOOL INVOLVING PROPERTIES OF THE MAYA NUMERAL SYSTEM}

\author{
Eliane Siviero da Silva ${ }^{1}$ \\ Universidade Estadual de Maringá - UEM \\ Lucieli M. Trivizoli ${ }^{2}$ \\ Universidade Estadual de Maringá - UEM
}

\begin{abstract}
Resumo
A História da Matemática ao ser utilizada como recurso didático juntamente com outros recursos pode oferecer uma importante contribuição ao processo de ensino e aprendizagem da Matemática. Este artigo apresenta uma proposta para o ensino de sistema de numeração para os Anos Iniciais do Ensino Fundamental fundamentada nos aspectos da História da Matemática. Vários povos desenvolveram sua própria forma de contagem e seu sistema de numeração. Os maias habitaram a América Central durante mais de mil anos e desenvolveram um sistema de numeração vigesimal (base 20) posicional, no qual o valor dos algarismos é determinado pela posição ocupada e também incluíram uma representação para o zero. A proposta apresentada neste artigo se caracteriza pelo desenvolvimento de atividades envolvendo propriedades do sistema de numeração Maia, utilizando materiais manipuláveis e foca nas relações entre contagem, conceito de agrupamento e esquema simbólico para escrever os números em determinado sistema de numeração. Dessa maneira, espera-se que este artigo se constitua uma referência aos professores, já que a quantidade de materiais que envolvem a História da Matemática nos primeiros anos do Ensino Fundamental ainda é incipiente. Além disso, estas atividades podem fornecer indícios para verificar se os alunos estão desenvolvendo suas compreensões sobre valor posicional, se estão integrando os conceitos de contagem e de agrupamento e se estão relacionando com seus registros numéricos.
\end{abstract}

Palavras-chave: História da Matemática; Sistema de numeração Maia; Anos Iniciais do Ensino Fundamental.

\section{Abstract}

The history of mathematics used as a teaching tool along with other resources can make an important contribution to the process of teaching and learning of mathematics. This paper presents a proposal for working with the numeral systems in the early years of

\footnotetext{
${ }^{1}$ Endereço eletrônico: elianesivierosilva@gmail.com

${ }^{2}$ Endereço eletrônico: 1mtrivizoli@uem.br
} 
elementary school based on aspects of the history of mathematics. Several civilizations have developed their own way of counting and their numeral systems. The Maya civilization lived in Central America for over a thousand years and developed a vigesimal (base-twenty) positional numeral system, in which the value of the symbols is determined by the position occupied and also it included a representation to zero. The suggestion presented in this paper is the development of activities connecting the properties of the Maya numeral system, using handle materials and focusing on the relation among counting and grouping concepts and symbolic scheme for writing the numbers in a numeral system. Thus, this paper aimed to be a reference to teachers, since the literature concerning the history of mathematics in the early years of elementary school it is not abundant. Moreover, these activities can provide evidence to verify that students are developing their understanding of place value, that they are integrating counting concepts and grouping and they are relating to their numerical records.

Keywords: History of Mathematics; Maya Numeral System; Elementary School.

\section{Introdução}

Neste artigo, temos a intenção de apresentar uma proposta para o ensino de sistema de numeração fundamentada nos aspectos da História da Matemática. Para uma compreensão completa do sistema de numeração decimal (hindu-arábico), as crianças precisam ter oportunidades de aprendizado sobre as ideias básicas de valor posicional, sobre os padrões para o modo que os números são formados, sobre composição e decomposição de números, sobre agrupamentos de unidades, dezenas e centenas, etc. Nossa proposta é do desenvolvimento de uma atividade envolvendo propriedades do sistema de numeração Maia, utilizando materiais manipuláveis, enfocando nas relações entre contagem, conceito de agrupamento e esquema simbólico para escrever os números em determinado sistema de numeração.

Nacarato, Mengali e Passos (2014) acreditam que a criação de um ambiente propício à aprendizagem seja algo fundamental para o movimento de produção de conhecimento matemático em sala de aula nos Anos Iniciais do Ensino Fundamental. Uma das características de um ambiente de aprendizagem diz respeito à relação dialógica que deve ser estabelecida em sala de aula entre os próprios alunos e entre eles e o professor. Essa relação deve priorizar um ambiente de compartilhamento de ideias e saberes, no qual o professor deve dar voz e ouvir o que os alunos têm a dizer, e ambos devem se envolver na atividade intelectual de produzir matemática, na qual o professor deixa de ser o único sujeito ativo e detentor do conhecimento, e os alunos são colocados no centro do processo de ensino-aprendizagem, tornando-se sujeitos ativos 
(NACARATO; MENGALI; PASSOS, 2014). Dessa forma, acreditamos que os Anos Iniciais seja o momento adequado para o trabalho com as diferentes metodologias e recursos didáticos para que os alunos percebam que não existe uma única forma de se aprender Matemática.

Segundo (MIGUEL, et al, 2009), a História da Matemática pode proporcionar essa autonomia para o aluno, esse ambiente de compartilhamentos de ideias. Além disso, outros argumentos são apontados para a utilização da História da Matemática em sala de aula, a saber: possibilita a desmistificação da Matemática como algo pronto e acabado, situa a Matemática como uma manifestação cultural, permite aos alunos compreenderem como os conceitos matemáticos se desenvolveram e sua evolução até os dias atuais, pode promover uma aprendizagem com mais significado e compreensiva da Matemática, possibilita a explicação do por que do surgimento de um determinado objeto, entre outros argumentos (MIGUEL; MIORIM, 2011; MIGUEL, 1997; MIGUEL, et al, 2009; D’AMBROSIO, 1996; MENDES, 2009).

Também encontramos argumentos de sua utilização nos Parâmetros Curriculares Nacionais (1997) que apontam que a incorporação da História da Matemática, como recurso didático juntamente com outros recursos e mediante um processo de transposição didática, pode oferecer uma importante contribuição ao processo de ensino-aprendizagem em Matemática. Os PCN consideram várias funções que a história pode desempenhar em situações de ensino, tais como desenvolver atitudes e valores mais favoráveis do aluno diante do conhecimento matemático, servir como um instrumento de resgate da própria identidade cultural, esclarecer ideias matemáticas que estão sendo construídas pelo aluno, especialmente para dar respostas a alguns "porquês" e, desse modo, contribuir para a constituição de um olhar mais crítico sobre os objetos de conhecimento (BRASIL, 1997).

Apesar de vários estudos e argumentos reforçadores sobre o uso didático da História da Matemática, "pouquíssimas são as ações no sentido de efetivar o estudo da História da Matemática pelos professores dos primeiros anos do Ensino Fundamental" (SANTOS, 2013, p. 152). E também "há ainda muito a se refletir sobre como utilizar os recursos e conhecimentos, até então obtidos de forma objetiva e sistemática no processo de ensino/aprendizagem" (SANTOS, 2013, p. 11). 
Nos Parâmetros Curriculares Nacionais (1997) é destacado que quando as crianças ingressam na vida escolar, elas já possuem um conhecimento razoável dos números naturais, e na prática escolar o mais comum é tentar explicar, logo de início, as ordens que compõem uma escrita numérica, unidade, dezena, centena, etc.

Embora isso possa parecer simples e natural do ponto de vista do adulto, que já conhece as regras de formação do sistema de numeração, o que se observa é que os alunos apresentam dificuldades nesse trabalho, deixando o professor sem compreender por que isso acontece (BRASIL, 1997, p. 62).

Sendo assim, entende-se que o recurso à história da numeração pode contribuir para um trabalho interessante com os números e, em especial, com o sistema de numeração (BRASIL, 1997).

\section{Sobre sistemas de numeração}

Segundo Eves (2011), desde a antiguidade, o processo de contar e o conceito de número já faziam parte da vida humana, antes mesmo de surgirem os primeiros registros históricos (há evidências arqueológicas de que o homem já há 50000 anos era capaz de contar). É possível admitir que mesmo os povos mais primitivos possuíam algum senso numérico, pelo menos ao ponto de reconhecer "mais" ou "menos" quando se acrescentavam ou retiravam alguns objetos de uma coleção, pois existem estudos que mostram que alguns animais são dotados desse senso (EVES, 2011).

Esta capacidade natural permite que esses animais reconheçam que um determinado conjunto numericamente reduzido, observado pela segunda vez, sofreu alguma modificação depois que um ou vários componentes foram acrescentados ou retirados (IFRAH, 1989). A história a seguir ilustra essa capacidade de distinção de um corvo:

Um castelão decidiu matar um corvo que fez seu ninho na torre do castelo. Já tentara várias vezes surpreender o pássaro, mas ao se aproximar o corvo deixava o ninho, instalava-se numa árvore próxima e só voltava quando o homem saía da torre. Um dia, o castelão recorreu a uma artimanha: fez entrar dois companheiros na torre. Instante depois, um deles desaparecia, enquanto o outro ficava. Mas, em vez de cair nesse golpe, o corvo esperava a partida do segundo para voltar a seu lugar. Da próxima vez ele fez entrar três homens, dos quais dois se afastaram em seguida: o terceiro pôde então esperar a ocasião para pegar o corvo, mas a esperta ave se mostrou ainda mais paciente que ele. Nas tentativas seguintes, recomeçou-se a experiência com quatro homens, sempre sem resultado. Finalmente, o estratagema teve sucesso com cinco pessoas, pois nosso corvo não conseguiu reconhecer mais que quatro homens ou quatro objetos...(IFRAH, 1989, p. 20). 
A história narrada demonstra que o senso numérico é limitado, o corvo conseguiu distinguir o conjunto de três homens do conjunto de quatro homens, porém, ele não conseguiu distinguir o conjunto de quatro homens do conjunto de cinco homens.

Esse senso numérico é mais desenvolvido nas pessoas do que no corvo da história, mas ele também é limitado. "Num rápido olhar, às vezes conseguimos diferenciar um montinho com cinco balas de outro com seis balas, mas não conseguimos diferenciar quinze balas de dezesseis balas. Para isso, precisamos fazer uma contagem" (IMENES; LELLIS, 1999, p. 10).

Assim, podemos considerar que "o senso numérico deve ter sido o ponto de partida para se aprender a contar" (IMENES; LELLIS, 1999, p. 10).

Conforme a sociedade evoluía, as primeiras formas de contagens se desenvolveram devido suas necessidades práticas, por exemplo, para uma tribo saber quantos eram seus membros e quantos eram seus inimigos, ou para um pastor saber se estava ou não faltando alguma ovelha de seu rebanho. Essa primeira forma de contagem era baseada em algum método simples de registro, estabelecida por uma relação biunívoca, por exemplo, se o pastor quisesse quantificar suas ovelhas podia-se dobrar um dedo para cada animal, fazer ranhuras no barro ou numa pedra, ou mesmo representar cada ovelha por uma pedra, produzir entalhes num pedaço de madeira ou fazer nós numa corda. "Então, talvez mais tarde, desenvolveu-se um arranjo de sons vocais para registrar verbalmente o número de objetos de um grupo pequeno. E mais tarde ainda, com o aprimoramento da escrita, foram surgindo arranjos de símbolos para representar esses números" (EVES, 2011, p. 26). Com o tempo tornou-se necessário efetuar contagens mais extensas e o processo de contar teve de ser sistematizado. Assim, vários povos desenvolveram sua própria forma de contagem e seu sistema de numeração. Dentre esses sistemas de numeração vale ressaltar que foram desenvolvidos sistemas de numeração posicionais (formados por agrupamentos de números conforme a base escolhida) e não posicionais.

\footnotetext{
Nos sistemas numéricos posicionais, todos os sistemas tiveram a escrita de seus números obedecendo a regras de ordem, sendo esta determinada pelo processo de correspondência empregado. A forma de escrever um número principiava em escolher certa base $\mathrm{X}$, e atribuir nomes aos números $1,2, \ldots$, $\mathrm{X}$-1. Para os números maiores do que $\mathrm{X}$, estes são escritos por operações dos números precedentes (SANTOS, 2013, p. 13).
} 
Dentre os diferentes sistemas de numeração de alguns povos, na atividade proposta neste artigo se trabalha com o sistema de numeração Maia, pois este sistema apresenta características importantes.

Os maias foram tribos que habitaram a América Central durante mais de mil anos (IMENIS; LELLIS, 1999). Desenvolveram um sistema de numeração vigesimal (base 20) posicional, no qual o valor dos algarismos é determinado pela posição ocupada e também havia uma representação para o zero (IFRAH, 1989).

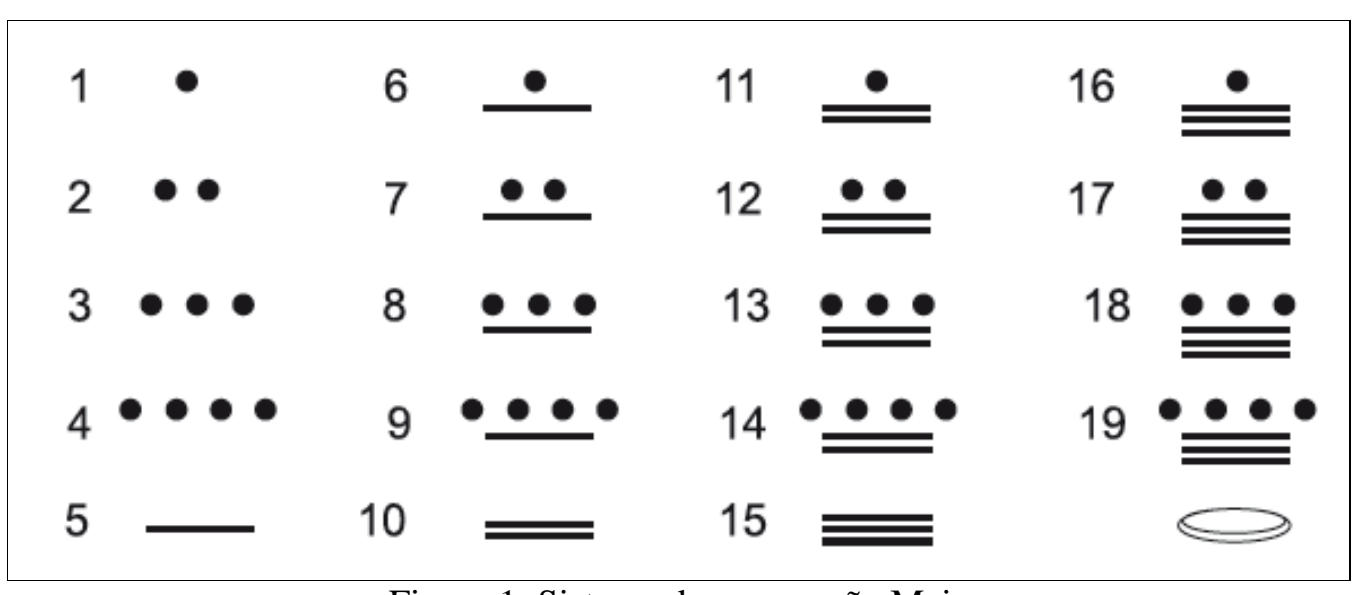

Figura 1: Sistema de numeração Maia

Esse sistema era representado por símbolos bem simples: pontos e traços. O zero era representado por uma concha, cada ponto representava uma unidade, as quatros primeiras unidades eram representadas de um a quatro pontos, o traço horizontal representava cinco unidades, um, dois, três ou quatro pontos acima do traço representavam seis, sete, oito e nove unidades, dois traços representam dez unidades e assim por diante (IFRAH, 1989).

O ponto era utilizado até quatro vezes e o traço horizontal até três vezes. Os valores superiores a 19 eram escritos numa coluna vertical, com uma fileira para cada ordem de unidades. Para os números compostos de duas ordens, o algarismo das unidades simples era colocado na parte de baixo e os algarismos das vintenas eram colocados na parte de cima (IFRAH, 1989). Assim, o número 20 era representado da seguinte forma:

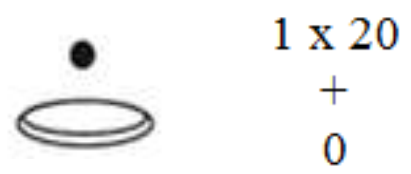


O ponto acima do zero equivale a 1 x 20 mais o zero é igual ao número 20 . Alguns outros números (IMENES; LELLIS, 1999, p. 37) eram representados como mostrado no quadro a seguir:

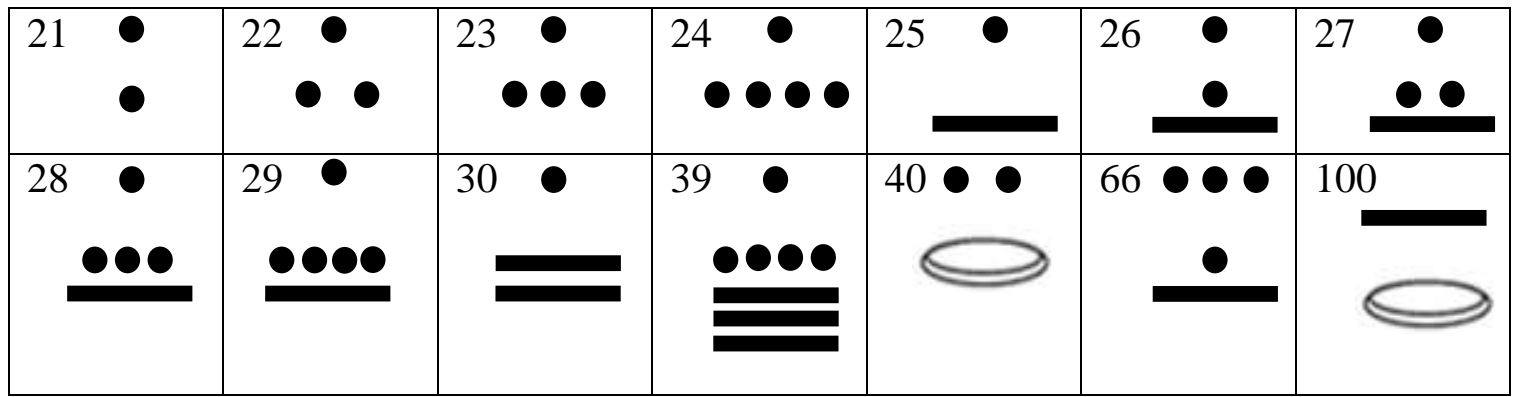

Quadro 1: Representação de números no sistema Maia

\section{Uma proposta de atividade}

Nesta atividade pretendemos desenvolver oportunidades para que os alunos façam conexões entre a contagem, o conceito de agrupamento e o esquema simbólico que usamos para escrever os números em determinado sistema de numeração.

Materiais necessários:

- Canudos para refrigerante cortados em pedaços de $9 \mathrm{~cm}$;

- Feijões;

- Copos plásticos (tamanho pequeno);

- Botões;

- Dados de 6 faces e 10 faces;

Os dados poderão ser confeccionados à mão, conforme o exemplo a seguir:
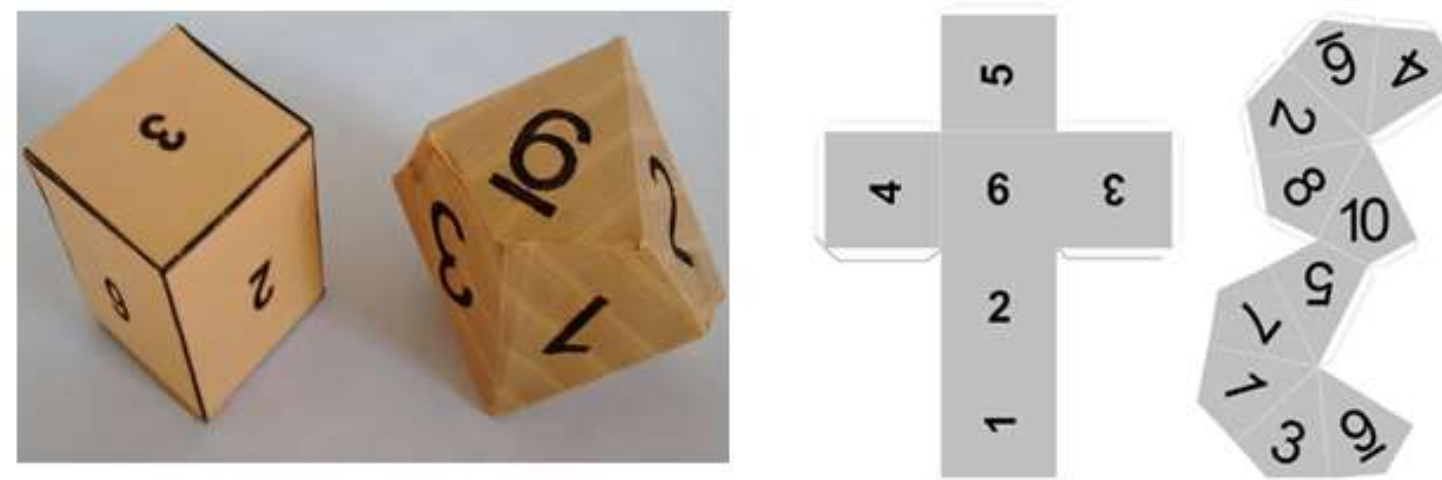

Figura 2: Dados de 6 faces e 10 faces e planificação

- Cartolina;

O professor deverá montar o sistema de numeração Maia na cartolina conforme sugerimos na próxima imagem: 


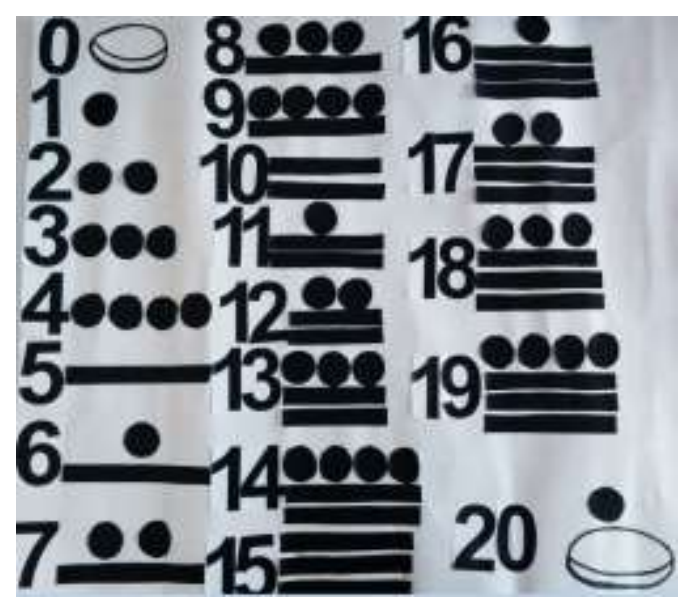

Figura 3: Sistema de numeração Maia

- Ficha.

A ficha deverá ser confeccionada da seguinte forma:

\begin{tabular}{|l|l|l|}
\hline Valor 1 & Valor 2 & Total \\
\hline & & \\
\hline & & \\
\hline
\end{tabular}

Tempo disponível:

2 aulas de 50 minutos.

Desenvolvimento:

Para iniciar a aula o professor poderá narrar para os alunos como o pastor fazia para contar seu rebanho quando ainda não existiam os números tais quais temos hoje. Para isso, poderá utilizar algumas pedras para auxiliá-lo na demonstração da situação, representando com cada pedra uma ovelha. Assim, o professor contará que, quando o pastor saía com o seu rebanho, representava cada uma de suas ovelhas por pedras. Em seguida, pode-se questionar os alunos se eles sabem dizer como o pastor faria para quantificar um número muito grande de ovelhas. Após sugestões dos alunos o professor pode encaminhar a ideia de que o pastor poderia pegar uma pedra maior que representasse certa quantidade de pedras menores, por exemplo, 5 pedras pequenas (relacionadas às 5 ovelhas) seriam representadas por uma pedra maior.

A partir dessa introdução, discuta sobre a necessidade de outras formas de representação para números 'grandes' e então o professor pode pedir para que cada aluno (ou grupo) pense em outra forma de quantificar os objetos sem utilizar as pedras. Os alunos deverão expor suas ideias para o restante da turma. Aproveitando esse 
Eliane Siviero da Silva e Lucieli M. Trivizoli

Uma Atividade para os Anos Iniciais envolvendo Propriedades do Sistema de Numeração Maia

momento, o professor deverá falar para os alunos que assim como eles acabaram de fazer, alguns povos também criaram uma forma específica de contagem, como os Romanos, os Egípcios, entre outros povos, incluindo-se os Maias (pode-se, aqui, apresentar características e imagens dessas civilizações).

Nesse momento o professor deverá apresentar o sistema de numeração Maia que foi confeccionado na cartolina, explicando como eles utilizavam agrupamentos de pontos e traços para representar os valores. Alguns destaques podem ser feitos sobre os números maiores que 19, representados na "vertical", ou seja, sobre a posição de cada símbolo determinando seu valor, e estabelecer semelhanças com nosso sistema decimal (base 10) em que a posição do número determina seu valor. Por exemplo, o algarismo 1 pode representar uma unidade, no número 15 ele representa uma dezena, no número 123 ele representa uma centena e assim por diante.

Após essas explicações o professor entregará para os alunos os canudos recortados, os feijões e os botões para que eles representem o sistema Maia por meio desses materiais: o canudo representará o traço (5 unidades), os feijões os pontos (1 unidade) e os botões o zero. Outra possibilidade para materiais a serem utilizados seriam pedras, gravetos e conchas.

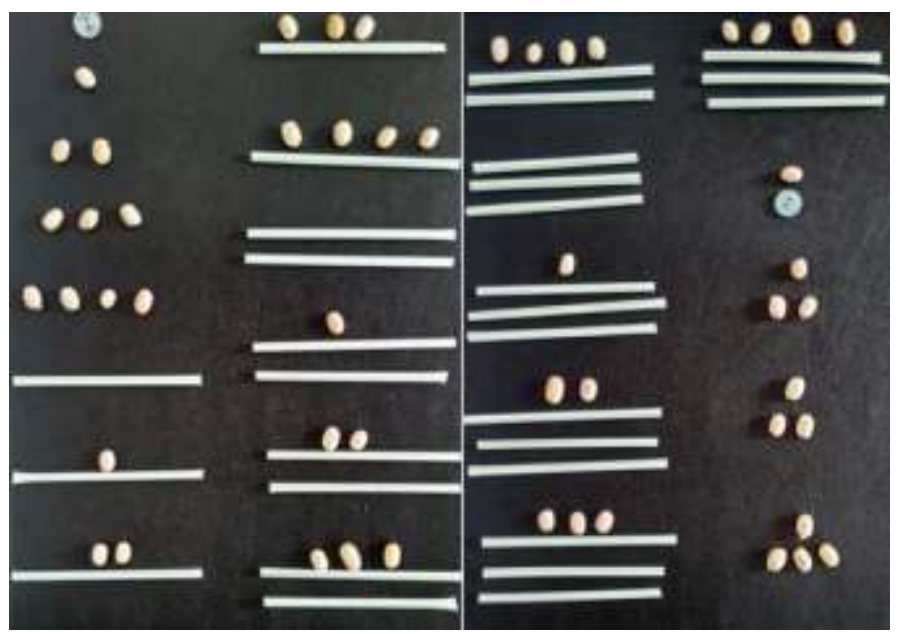

Figura 4: Representação do sistema Maia com canudos, feijões e botões

Depois de os alunos trabalharem com essa representação, será desenvolvida uma atividade $^{3}$ em duplas. Cada dupla receberá uma ficha para fazerem anotações e um dado de 6 faces. Aproveitando os canudos e os feijões que já foram entregues, o professor

\footnotetext{
${ }^{3}$ Atividade adaptada do livro Matemática no Ensino Fundamental: Formação de professores e aplicações em sala de aula (VAN DE WALLE, 2009).
} 
deverá explicar que o primeiro aluno irá jogar o dado, representar esse valor conforme o sistema Maia e anotá-lo na ficha no campo Valor 1, essa anotação será feita por meio de desenhos, por exemplo, se o aluno jogar o dado e cair o valor 3, ele deverá representá-lo por três feijões e desenhar na ficha. O segundo aluno também irá jogar o dado representar o valor indicado na face e anotá-lo. Em seguida, eles deverão encontrar a quantidade total somando os dois valores e representá-los conforme o sistema de numeração Maia. A seguir temos um exemplo de preenchimento da ficha.

\begin{tabular}{|c|c|c|}
\hline Valor 1 & Valor 2 & Total \\
\hline$\bullet \bullet \bullet$ & $\bullet \bullet \bullet \bullet$ & $\bullet \bullet$ \\
\hline
\end{tabular}

Essa mesma atividade será novamente aplicada, só que agora pensando no sistema de numeração decimal. Para isso os alunos receberão dados de dez lados e copos plásticos, sendo que os feijões continuarão valendo uma unidade e os copos plásticos 10 unidades. O processo será o mesmo: um aluno por vez irá jogar o dado, representar o valor e anotá-lo; só que agora a representação será feita por agrupamentos de 10 em 10, serão utilizados feijões para representar valores até o 9 e o 10 será representado por um copo plástico, e os demais valores serão representados por meio de composições de copos plásticos e feijões.

Para a conclusão, o professor poderá fazer uma discussão com os alunos, pedindo a eles que falem/expliquem como cada sistema de numeração possui características próprias, que o nosso sistema é um sistema decimal, formado por agrupamentos de 10 e posicional, no qual a posição ocupada pelo número determina seu valor, etc.

\section{Considerações}

Segundo Van de Walle (2009, p. 216), “A contagem desempenha um papelchave na construção das ideias de base dez sobre quantidades e na associação desses conceitos aos símbolos e aos nomes orais para os números”. Este mesmo autor, baseado em Thompson (1990), destaca que as crianças podem contar conjuntos de três modos diferentes: contagem por unidades, contagem por agrupamentos e unidades, e contagem por dezenas e unidades. Os métodos de contagem fornecem um mecanismo de conexão com o conceito de agrupamento (de dezenas para o sistema numérico decimal) e com o esquema simbólico que usamos para escrever os números. 
O objetivo principal destas atividades é que os alunos compreendam a noção de agrupamentos e a noção de valor posicional. Dessa maneira, o professor pode obter indícios para verificar se os alunos estão desenvolvendo suas compreensões sobre valor posicional integrando os conceitos de contagem e de agrupamento e se estão relacionando com seus registros numéricos.

Estudar sistemas de numeração antigos pode ser um tema interessante de estudo para alunos: eles podem aprender mais sobre a característica do nosso próprio sistema relacionando-as com outros sistemas. Além disso, eles podem aprender mais sobre essas civilizações antigas e compreender melhor como eles lidavam com os números.

\section{Referências}

BRASIL, Secretaria de Educação Básica. Parâmetros Curriculares Nacionais. Matemática. Brasília: MEC; SEB, 1997.

D’AMBROSIO, Ubiratan. História da Matemática e Educação. Caderno Cedes 40 História e Educação Matemática. 1. ed. Campinas: Papirus, 1996.

EVES, Howard. Introdução à História da Matemática. Campinas: Editora da Unicamp, 2011.

IFRAH, Georges. Os números: a história de uma grande invenção. 3. ed. São Paulo: Globo, 1989.

IMENES, Luiz Márcio; LELLIS, Marcello. Os números na história da civilização. São Paulo: Scipione, 1999.

MENDES, Iran Abreu. Matemática e investigação em sala de aula: tecendo redes cognitivas na aprendizagem. São Paulo: Editora Livraria da Física, 2009.

MIGUEL, Antônio. As potencialidades pedagógicas da história da matemática em questão: argumentos reforçadores e questionadores. Zetetiké - Cempem - Fe/Unicamp, v. 5 , n. 8, p.73-105, 1997.

MIGUEL, Antônio et al. História da Matemática em atividades didáticas. 2. ed. São Paulo: Editora Livraria da Física, 2009.

MIGUEL, Antônio; MIORIM, Maria Ângela. História na Educação Matemática: propostas e desafios. 2. ed. Belo Horizonte: Autêntica Editora, 2011.

NACARATO, Adair Mendes; MENGALI, Brenda Leme da Silva; PASSOS, Carmen Lúcia Brancaglion. A matemática nos anos iniciais do ensino fundamental: tecendo fios do ensinar e do aprender. 2. ed. Belo Horizonte: Autêntica Editora, 2014. 
SANTOS, Anderson Oramísio. História da matemática como metodologia alternativa para o desenvolvimento da prática pedagógica nos primeiros anos do ensino fundamental. 2013. 175 f. Dissertação (Mestrado) - Programa de PósGraduação em Educação, Universidade Federal de Uberlândia, Uberlândia, 2013.

WALLE, John A. Van de. Matemática no Ensino Fundamental: Formação de professores em sala de aula. Porto Alegre: Artmed, 2009. 